\title{
Predicting Tidal Currents Using 25-h Observations through a Complete Tidal Species Modulation with Tidal Current Constant Corrections Method
}

\author{
DO-SEONG BYUN \\ Ocean Research Division, Korea Hydrographic and Oceanographic Agency, Busan, Republic of Korea \\ DEIRDRE E. HART \\ Department of Geography, University of Canterbury, Christchurch, New Zealand
}

(Manuscript received 14 July 2018, in final form 19 September 2018)

\begin{abstract}
A new approach enabling the prediction of tidal currents, for observation sites with as little as $\geq 25 \mathrm{~h}$ of data, has been developed as a practical way of utilizing very short tidal current records. We name this technique the complete tidal species modulation with tidal current constant corrections (CTSM+TCCC) method. In addition to a short-term tidal current record from the "observation site," this technique also requires (i) ideally half a year (specifically, $\geq 183$ days from any time) and (ii) concurrent ( $\geq 25 \mathrm{~h}$ ) sea level observation records from a nearby "reference site." The reliability of the CTSM+TCCC method is tested for three different tidal current regimes (almost rectilinear, elliptical, and near circular) in Geyonggi Bay, South Korea, using daily slices ( $25 \mathrm{~h}$ long) of 29-day tidal current records from each observation station, plus sea level records from the nearby Incheon reference station. RMSE analysis of the resulting prediction time series demonstrates that the CTSM+TCCC method produces reasonably accurate predictions based on observation station records derived from spring, but not neap, tide periods. We conclude that our method can be successfully employed to make tidal current predictions using 25 -h observation station records obtained from spring tide periods, ideally gathered during periods of relatively calm weather. As well as testing the sensitivity of CTSM+TCCC predictions to observation record timing, the effect of reference station location was investigated using records from 20 stations spread along the South Korean coasts. Results revealed that tidal records from nearby tidal current observation and sea level reference stations produce reasonable current predictions, since proximal locations share similar tidal species' modulated tidal and tidal current behaviors.
\end{abstract}

\section{Introduction}

In tidally dominated coastal regimes worldwide, tidal and tidal current predictions are vitally important for safe navigation, the planning and management of coastal development, the design and construction of sea structures, research, and rescue and military operations. In general, obtaining long-term tidal current observation records for new coastal regimes is no small task, since equipment, installation, and monitoring costs are very expensive, and moored instruments are frequently lost or damaged by fisheries and other maritime activities. Thus, internationally, tidal current observations are commonly recorded over short time periods of less than a month. Up until 2016 the Korea Hydrographic

\footnotetext{
Corresponding author: Do-Seong Byun, dsbyun@korea.kr
}

and Oceanographic Agency (KHOA), for example, measured the majority of its tidal current records over 25-h spring tide periods (1263 stations), with far fewer of its records exceeding 30 days (361 stations). These $25-\mathrm{h}$ records were used to calculate maximum flood and ebb currents for dissemination on nautical charts and to calculate 12-hourly (lunar cycle) tidal currents during spring and neap tides for a tide (tidal stream) atlas. Considering more practical uses for the many short-term tidal current observation records, held by KHOA and other ocean or hydrographic agencies worldwide, is the motivation behind the present study.

In a related paper, Byun and Hart (2015) proposed a hybrid technique for predicting tidal heights based on $\geq 25$-h concurrent "temporary" and "reference" site sea level observations plus 28 days to a year of reference tide records, termed the complete tidal species 
modulation with tidal constant corrections (CTSM+TCC) method. This method successfully predicted tidal heights based on 25-h sea level input data sampled during spring tide observation periods at times of the year when overall daily tidal ranges are relatively high, thereby overcoming the record-length limitations of traditional standard harmonic-based prediction methods, such as $\mathrm{T}_{-}$Tide by Pawlowicz et al. (2002).

Similar to in tide analysis and prediction, tidal current studies harmonically analyze the $u$ and $v$ velocity components of records so that the results may be used to predict tidal currents. Harmonic analysis of 15-day or monthlong tidal current observation records can be employed in conventional tidal (current) harmonic analysis and prediction programs, including the Institute of Ocean Sciences (IOS) tidal current package (Foreman 1978) and the MATLAB version of Pawlowicz et al.'s (2002) T_Tide package. These programs use the inference technique, with inference parameters (i.e., the ratios of inferred to reference amplitudes, and the phase-lag differences between reference phase lags and inferred phase lags) calculated from harmonic analysis of long-term sea level records ( $\geq 183$-day) from a nearby reference tidal station, in order to forcibly separate out the new station's inferred constituents. In terms of inference input data, it is well recognized that long-term tidal current-derived values from a nearby reference tidal current observation station are preferable, but longterm sea level-derived values from a nearby reference tidal observation station can be used where such longterm current data are unavailable (Foreman 1978; Byun 2011).

Accordingly, in this paper, we have used long-term sea level records observed at nearby tidal observation stations in order to test the CTSM+TCCC method. In section 2 we introduce a conventional tidal current analysis method employed on 25-h observation records, and explain its tidal current prediction shortcomings. Then in section 3 we explain our new approach, showing validated prediction results for three tidal current observation stations, each with one month of observations and characterized by different flow patterns. In addition, we explore the tidal current prediction capability of the CTSM+TCCC method with sea level records from spatially differentiated reference tidal stations along the west and south coasts of South Korea, and discuss the main differences in results generated using this method compared to those derived from traditional harmonic prediction methods using longer ( 29 day) tidal current records.

\section{Traditional tidal current analysis of $25-h$ records}

A recorded time series of 10-min interval, 25-h duration, current velocity $\mathbf{U}(t)$ observations can be expressed in complex vector notation as

$$
\mathbf{U}(t)=u(t)+i v(t)
$$

where $u$ and $v$ are the $x$ - and the $y$-direction velocity components, respectively; $i=\sqrt{-1}$; and $t$ is time.

Each velocity component $\left[u(t)\right.$ or $v(t)$, i.e., $\left.U_{u, v}(t)\right]$ in Eq. (1) can be expressed from Fourier series (Emery and Thomson 1998) using the three main tidal constituents (diurnal, semidiurnal, and fourth diurnal) as

$$
\begin{aligned}
U_{u, v}(t)= & \overline{U_{u, v}(t)}+\sum_{j=1,2,4}\left[A_{j}^{u, v} \cos \left(\omega_{j} t\right)\right. \\
& \left.+i B_{j}^{u, v} \cos \left(\omega_{j} t\right)\right]
\end{aligned}
$$

where the mean value of $U_{u, v}(t)$ for the 25-h records in solar time is

$$
\overline{U_{u, v}}=\frac{1}{T} \sum_{t=0}^{T} U_{u, v}(t),
$$

and each pair of Fourier coefficients $\left(A_{j}^{u, v}, B_{j}^{u, v}\right)$ for each velocity component ( $u$ or $v$ ) can be calculated as

$$
\begin{array}{ll}
A_{j}^{u, v}=\frac{2}{T} \sum_{t=0}^{T} U_{u, v}(t) \cos \left(\omega_{j} t\right), & j=1,2,4, \\
B_{j}^{u, v}=\frac{2}{T} \sum_{t=0}^{T} U_{u, v}(t) \sin \left(\omega_{j} t\right), & j=1,2,4,
\end{array}
$$

where $T=N \Delta t, N$ is the number of data values, and $\Delta t$ is the data interval in solar hours. Note that $\omega_{1}=14.4920521^{\circ} \mathrm{h}^{-1}, \omega_{2}=28.9841042^{\circ} \mathrm{h}^{-1}, \omega_{4}=$ $57.9682084^{\circ} \mathrm{h}^{-1}$ in solar hours; or $\omega_{1}=15^{\circ} \mathrm{h}^{-1}$, $\omega_{2}=30^{\circ} \mathrm{h}^{-1}, \omega_{4}=60^{\circ} \mathrm{h}^{-1}$ in lunar hours (since 1 lunar hour $=1.0350501$ solar hours).

Equation (2) can be expressed as the compact Fourier series form, with amplitudes and phases calculated from the inverse relationship between the Fourier coefficients $\left(A_{j}^{u, v}, B_{j}^{u, v}\right)$ in Eqs. (4) and (5), as given by

$$
U_{u, v}(t)=\overline{U_{u, v}}+\sum_{j=1,2,4} C_{j}^{u, v} \cos \left(\omega_{j} t-\theta_{j}^{u, v}\right),
$$

where the amplitude $C_{j}^{u, v}$ of the $j$ th component is calculated by

$$
C_{j}^{u, v}=\sqrt{\left(A_{j}^{u, v}\right)^{2}+\left(B_{j}^{u, v}\right)^{2}}
$$


and the phase lag $\theta_{j}^{u, v}$ of the $j$ th component at time $t=0$ is calculated by

$$
\theta_{j}^{u, v}=\tan ^{-1}\left(\frac{B_{j}^{u, v}}{A_{j}^{u, v}}\right)
$$

For convenience, $t$ denotes the solar-day starting point of the observation record ( $00 \mathrm{~h}: 00 \mathrm{~min}: 00 \mathrm{~s})$.

Tidal current velocities for the tidal diamonds table of a nautical chart and/or tide atlas can be calculated using Eq. (6) for each solar mean hour before $(\tau=-1,-2,-3,-4,-5,-6)$ and after $(\tau=+1,+2,+3,+4,+5,+6)$ high water $(\tau=0)$ at the reference station [or for each lunar hour $\left(\tau^{\prime}=0,+1,+2, \ldots,+12\right)$ after the moon's transit time $\left(\tau^{\prime}=0\right)$, which is derived from a lookup table or calculation referenced to the observation time zone]. An adjustment factor is conventionally used to calculate yearly maximum flood or ebb current velocities, using the ratio of the maximum tidal range to the observed tidal range from a nearby reference tidal station.

However, tidal currents cannot be accurately predicted for just any time period using Eq. (6) with 25-h tidal current records observed during spring tide periods, using one tidal current harmonic constant for each tidal current species. This is because, in order to generate spring-neap tidal currents including their monthly inequalities, at least three tidal current harmonic constants $\left(\mathrm{M}_{2}, \mathrm{~S}_{2}\right.$, and $\left.\mathrm{N}_{2}\right)$ are required, and 15-daylong (or 28daylong) records are needed to harmonically separate the $\mathrm{M}_{2}$ tide from the $\mathrm{S}_{2}$ (or from the $\mathrm{N}_{2}$ ) tide. Thus, 25-h tidal current records are not, on their own, sufficient for properly generating and predicting tidal currents. In the next section, we demonstrate a modified prediction approach that overcomes this data limitation.

\section{Complete tidal species modulation with tidal current constant corrections}

In this section we explore a new approach to predicting tidal currents using 25-h tidal current records for a new observation station. In a previous study, Byun and Hart (2015) demonstrated that tidal heights for a new observation tidal station $\eta_{o}(\tau)$ can be predicted by the CTSM method, using an embedded nodal correction, a modulated tidal height amplitude $A_{o \eta}^{s}(\tau)$, and a modulated tidal height phase lag $\varphi_{o \eta}^{s}(\tau)$ for each tidal species (with species denoted by the superscript $s$ ) over the total tidal species (denoted by the superscript $m$ ) according to

$$
\eta_{o}(\tau)=\sum_{s=1}^{m} A_{o \eta}^{s}(\tau) \cos \left[\omega_{R}^{s} t-\varphi_{o \eta}^{s}(\tau)\right]
$$

with

$$
A_{o \eta}^{s}(\tau)=\sqrt{\sum_{i=1}^{k}\left[f(\tau)_{i}^{s} a_{i}^{s}\right]^{2}+2 \sum_{i>j \text { or } i<j}^{k}\left[f(\tau)_{i}^{s} a_{i}^{s}\right]\left[f(\tau)_{j}^{s} a_{j}^{s}\right] \cos \left\{\left(\omega_{i}^{s}-\omega_{j}^{s}\right) t+\left[V\left(t_{0}\right)_{i}^{s}+u(\tau)_{i}^{s}-g_{i}^{s}\right]+\left[V\left(t_{0}\right)_{j}^{s}+u(\tau)_{j}^{s}-g_{j}^{s}\right]\right\}},
$$

and

$$
\varphi_{o \eta}^{s}(\tau)=\tan ^{-1}\left\{\frac{\sum_{i=1}^{k} a_{i}^{s} \sin \left[\left(\omega_{i}^{s}-\omega_{R}^{s}\right) t+V\left(t_{0}\right)_{i}^{s}+u(\tau)_{i}^{s}-g_{i}^{s}\right]}{\sum_{i=1}^{k} a_{i}^{s} \cos \left[\left(\omega_{i}^{s}-\omega_{R}^{s}\right) t+V\left(t_{0}\right)_{i}^{s}+u(\tau)_{i}^{s}-g_{i}^{s}\right]}\right\},
$$

where $i$ and $j$ denote each tidal constituent; $k$ is the number of tidal constituents; subscript on denotes the tidal observation station; and $\omega_{i}^{s}$ and $\omega_{R}^{s}$ are the angular frequencies of a tidal constituent and of representative tidal constituents for each species, respectively (e.g., the dominant $\mathrm{K}_{1}, \mathrm{M}_{2}$, and $\mathrm{M}_{4}$ constituents may be used as representative diurnal, semidiurnal, and fourth-diurnal species, respectively). In addition, $a_{i}^{s}$ and $g_{i}^{s}$ are the tidal harmonic amplitude and phase lag, respectively; $f(\tau)_{i}^{s}$ is the nodal factor; $u(\tau)_{i}^{s}$ is the nodal angle; $V\left(t_{0}\right)_{i}^{s}$ indicates the astronomical arguments; and $\tau\left(=t_{0}+t\right)$ is the reference time $t_{0}$ plus the $t$ elapsed since $t_{0}$. Note that $A_{o \eta}^{s}(\tau)$ and $\varphi_{o \eta}^{s}(\tau)$ can be more accurately predicted using tidal harmonic constants derived from long-term records.

For a short-term ( $\geq 25 \mathrm{~h}$ ) temporary sea level observation station, tides can be relatively accurately predicted, using the $A_{r \eta}^{s}(\tau)$ and $\varphi_{r \eta}^{s}(\tau)$ from a nearby reference tidal station (subscript $r \eta$ ) and the relationships of the tidal amplitude ratio $\left[A_{o \eta}^{s}(\tau) / A_{r \eta}^{s}(\tau)=a_{o \eta}^{s} / a_{r \eta}^{s}\right]$ and the tidal phaselag difference $\left[\varphi_{o \eta}^{s}(\tau)-\varphi_{r \eta}^{s}(\tau)=g_{o \eta}^{s}-g_{r \eta}^{s}\right]$ between the modulated $\left[A_{o \eta}^{s}(\tau), A_{r \eta}^{s}(\tau)\right]$ and representative tidal 
amplitudes $\left(a_{o \eta}^{s}, a_{r \eta}^{s}\right)$ and between the modulated $\left[\varphi_{o \eta}^{s}(\tau), \varphi_{r \eta}^{s}(\tau)\right]$ and representative tidal phase lags $\left(g_{o \eta}^{s}, g_{r \eta}^{s}\right)$ for each tidal species. Note that the modulated tidal amplitudes and phase lags are more precisely derived from sea level input data concurrently observed during spring tide periods and calm synoptic weather conditions at the temporary and reference tidal stations (Byun and Hart 2015) to minimize nontidal residual error influences.

Therefore, $A_{o \eta}^{s}(\tau)$ in Eq. (10) and $\varphi_{o \eta}^{s}(\tau)$ in Eq. (11) can be expressed as

$$
\begin{aligned}
& A_{o \eta}^{s}(\tau)=A_{r \eta}^{s}(\tau)\left(\frac{a_{o \eta}^{s}}{a_{r \eta}^{s}}\right), \\
& \varphi_{o \eta}^{s}(\tau)=\varphi_{r \eta}^{s}(\tau)+g_{o \eta}^{s}-g_{r \eta}^{s} .
\end{aligned}
$$

Substituting Eqs. (12) and (13) into Eq. (9), the $\eta_{o}(\tau)$ of Eq. (9) can be expressed as

$$
\begin{aligned}
\eta_{o}(\tau)= & \sum_{s=1}^{m} A_{r \eta}^{s}(\tau)\left(\frac{a_{o \eta}^{s}}{a_{r \eta}^{s}}\right) \cos \left\{\omega_{R}^{s} t\right. \\
& \left.-\left[\varphi_{r \eta}^{s}(\tau)+g_{o \eta}^{s}-g_{r \eta}^{s}\right]\right\} .
\end{aligned}
$$

Following the same approach for tidal currents as that applied to tide levels in Eq. (14), the tidal current velocity $\mathbf{U}_{o}$ data from a temporary tidal current observation station (subscript $o$ ) is separated into its $u_{o}(\tau)$ and $v_{o}(\tau)$ velocity components. Then each velocity component may be predicted using the $A_{r \eta}^{s}(\tau)$ and $\varphi_{r \eta}^{s}(\tau)$ values from a reference tidal station, plus the relationship of the amplitude ratio $\left[A_{o U\left(u_{-} \_{ }_{-} \_v\right)}^{s}(\tau) / A_{r \eta}^{s}(\tau)=a_{o U\left(u_{-} \text {or } \_v\right)}^{s} / a_{r \eta}^{s}\right]$ and the phase-lag difference $\left[\varphi_{o U\left(u_{\_} \text {or_ } v\right)}^{s}(\tau)-\varphi_{r \eta}^{s}(\tau)=g_{o U\left(u_{-} \text {or_v } v\right)}^{s}-g_{r \eta}^{s}\right]$ between the modulated amplitudes $\left[A_{o U\left(u_{\_} o_{-} v\right)}^{s}(\tau), A_{r \eta}^{s}(\tau)\right]$ and the representative amplitudes $\left[a_{o U\left(u_{-}-r_{-} v\right)}^{s}, a_{r \eta}^{s}\right]$, and between the modulated phase lags $\left[\varphi_{o U\left(u_{-} \text {or } \_v\right)}^{s}(\tau), \varphi_{r \eta}^{s}(\tau)\right]$ and the representative phase lags $\left[g_{o U\left(u_{-}-r_{-} v\right)}^{s}, g_{r \eta}^{s}\right]$ for each tidal current velocity and tidal height species. These representative amplitudes and phase lags are derived from harmonic analysis of tidal current velocity data from a temporary observation station plus sea level data from a reference station, both datasets having been concurrently observed during the same spring tide period, ideally under calm synoptic weather conditions. Accordingly, each tidal current velocity component $\left[u_{o}(\tau)\right.$ and $\left.v_{o}(\tau)\right]$ can be predicted by

$u_{o}(\tau)=\sum_{s=1}^{m} A_{r \eta}^{s}(\tau)\left(\frac{a_{o u}^{s}}{a_{r \eta}^{s}}\right) \cos \left\{\omega_{R}^{n} t-\left[\varphi_{r \eta}^{s}(\tau)+g_{o u}^{s}-g_{r \eta}^{s}\right]\right\}$,

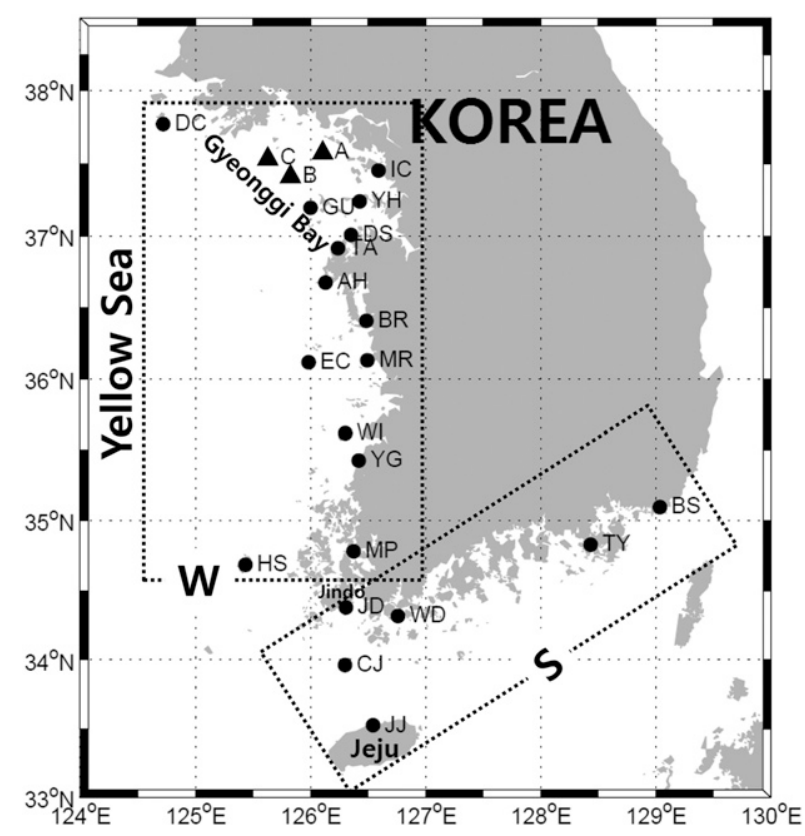

FIG. 1. Map showing locations of three tidal current observation stations (triangles) in Gyeonggi Bay (stations A-C) and 20 tidal observation stations (circles), where sea level data are recorded longterm, along the south and west coasts of South Korea.

$v_{o}(\tau)=\sum_{s=1}^{m} A_{r \eta}^{s}(\tau)\left(\frac{a_{o v}^{s}}{a_{r \eta}^{s}}\right) \cos \left\{\omega_{R}^{n} t-\left[\varphi_{r \eta}^{s}(\tau)+g_{o v}^{s}-g_{r \eta}^{s}\right]\right\}$.

\section{Prediction experiment setup}

Producing tidal current predictions based on our CTSM+TCCC method necessitates three datasets: 25-h tidal current records from a temporary observation station (the prediction station), concurrent sea level records observed at a nearby reference station, and long-term ( $>6$ month, from any time period) sea level records also from the reference station.

To represent the possible diversity of temporary tidal prediction stations, we selected prediction sites characterized by the three different archetypal tidal current types found in Gyeonggi Bay, South Korea (Fig. 1): one station each with almost rectilinear, elliptical, and near-circular flow patterns (Fig. 2). Calculated tidal ellipses for these three stations show that the semidiurnal tidal currents predominate (particularly, the $\mathrm{M}_{2}$ tidal current constituent dominates, followed by significant other contributions from the $\mathrm{S}_{2}$ and the $\mathrm{N}_{2}$ tidal current constituents), with the diurnal $\left(\mathrm{K}_{1}\right.$ and $\left.\mathrm{O}_{1}\right)$ and fourth-diurnal $\left(\mathrm{M}_{4}\right)$ tidal currents sharing similar but relatively weaker magnitudes (Table 1). The calculated tidal current ellipses 


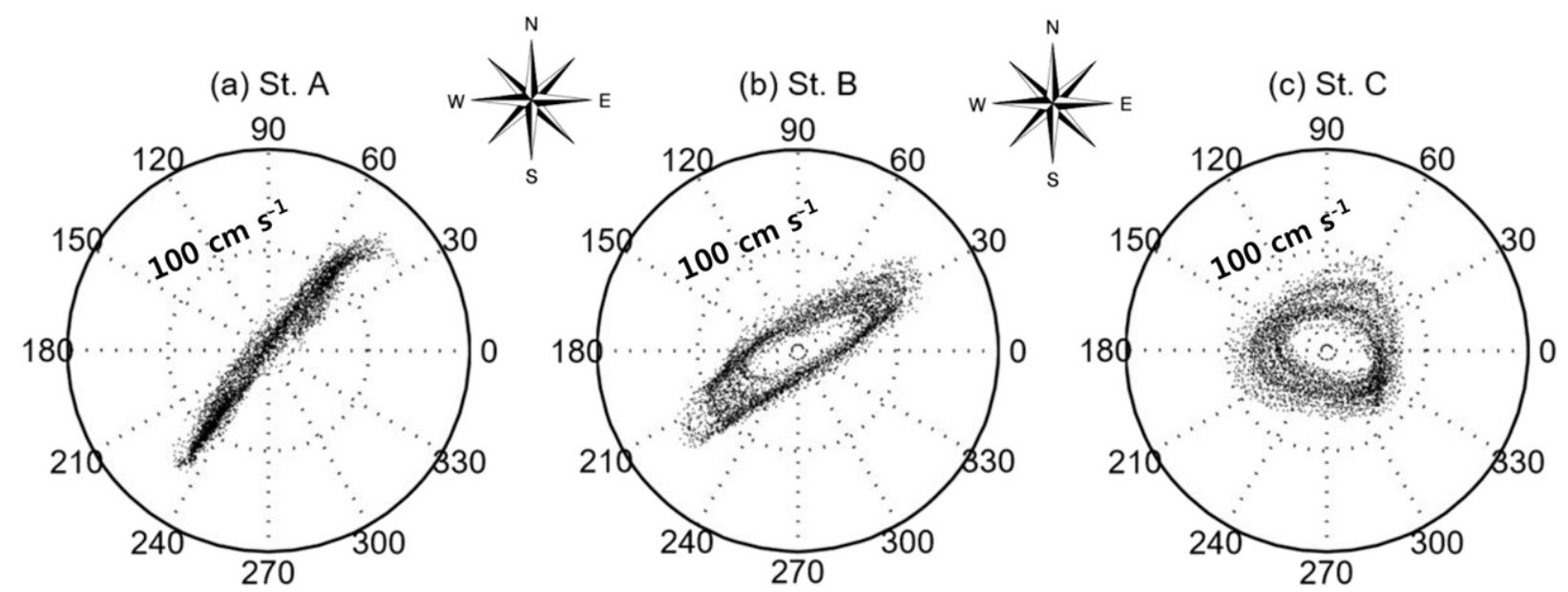

FIG. 2. (a)-(c) Scatterplots of tidal currents observed over the 29 days between 13 May and 10 Jun 2007, at stations A-C in Gyeonggi Bay, revealing almost rectilinear, elliptical, and near-circular patterns, respectively.

exhibited $\mathrm{M}_{2}$ eccentricities (i.e., ratios of the $\mathrm{M}_{2}$ "semimajor" to "semiminor" axes) of 0.06 for station A, 0.28 for station B, and 0.79 for station C. Hereafter, these tidal current types are referred to by the following labels: almost rectilinear, elliptical, and near circular.

The tidal current data used in these experiments were recorded by KHOA on Aanderaa RCM9 instruments positioned $5 \mathrm{~m}$ below sea level, operating at a sampling interval of $10 \mathrm{~min}$, for the 29-day period from 13 May to 10 June 2007. From each observation record, we produced 29 "daily" tidal current data slices, that is, 25 -h tidal current record slices starting at $0000 \mathrm{~h}$. In addition, we subsampled KHOA's 2007 sea level data from a reference station, station IC, over the same time period, to make 29 concurrent daily $(25 \mathrm{~h})$ reference station sea level data slices.

Each concurrent pair of temporary observation station tidal current velocities and reference station sea levels was harmonically analyzed in order to produce the input values

TABLE 1. Six major tidal current ellipse results for diurnal, semidiurnal, and fourth-diurnal harmonic constituents from harmonic analysis of 29-day tidal current observations over the 29 days from 13 May to 10 Jun 2007 recorded at three neighboring stations in Gyeonggi Bay, South Korea. Note that $a_{\max }, b_{\min }, \Phi, \phi$, and $\varepsilon_{c}$ denote the semimajor axis, semiminor axis, inclination, phase, and eccentricity $\left(b_{\min } / a_{\max }\right)$, respectively; $\phi$ is referenced to $135^{\circ} \mathrm{E}$. The inference method is applied to separate out the $\mathrm{S}_{2}\left(\mathrm{~K}_{1}\right)$ and $\mathrm{K}_{2}\left(\mathrm{P}_{1}\right)$ tidal current constituents using the inference parameters calculated from 1-yr harmonic analysis of the nearby Incheon tidal station sea level records.

\begin{tabular}{|c|c|c|c|c|c|c|c|}
\hline Station & Constituent & $a_{\max }\left(\mathrm{cm} \mathrm{s}^{-1}\right)$ & $b_{\min }\left(\mathrm{cm} \mathrm{s}^{-1}\right)$ & $\Phi\left(^{\circ}\right)$ & $\phi\left(^{\circ}\right)$ & $\varepsilon_{c}$ & $\begin{array}{l}\text { Tidal current } \\
\text { cycle shape }\end{array}$ \\
\hline \multirow[t]{6}{*}{ A } & $\mathrm{M}_{2}$ & 108 & 6 & 51 & 63 & 0.06 & Almost rectilinear \\
\hline & $\mathrm{S}_{2}$ & 38 & 2 & 50 & 127 & 0.05 & \\
\hline & $\mathrm{N}_{2}$ & 17 & 0.1 & 50 & 32 & 0.01 & \\
\hline & $\mathrm{K}_{1}$ & 8 & 1 & 50 & 224 & 0.08 & \\
\hline & $\mathrm{O}_{1}$ & 5 & 0.2 & 53 & 176 & 0.04 & \\
\hline & $\mathrm{M}_{4}$ & 6 & 4 & 46 & 201 & 0.65 & \\
\hline \multirow[t]{6}{*}{ B } & $\mathrm{M}_{2}$ & 97 & 27 & 32 & 54 & 0.28 & Elliptical \\
\hline & $\mathrm{S}_{2}$ & 34 & 8 & 38 & 118 & 0.23 & \\
\hline & $\mathrm{N}_{2}$ & 16 & 5 & 36 & 23 & 0.33 & \\
\hline & $\mathrm{K}_{1}$ & 7 & 2 & 51 & 222 & 0.24 & \\
\hline & $\mathrm{O}_{1}$ & 5 & 1 & 59 & 183 & 0.2 & \\
\hline & $\mathrm{M}_{4}$ & 5 & -1 & 20 & 81 & -0.25 & \\
\hline \multirow[t]{6}{*}{$\mathrm{C}$} & $\mathrm{M}_{2}$ & 62 & 49 & 171 & 195 & 0.79 & Near circular \\
\hline & $\mathrm{S}_{2}$ & 21 & 16 & 29 & 109 & 0.76 & \\
\hline & $\mathrm{N}_{2}$ & 10 & 9 & 111 & 99 & 0.84 & \\
\hline & $\mathrm{K}_{1}$ & 7 & 2 & 75 & 243 & 0.22 & \\
\hline & $\mathrm{O}_{1}$ & 6 & 2 & 74 & 194 & 0.30 & \\
\hline & $\mathrm{M}_{4}$ & 7 & -0.7 & 71 & 191 & -0.10 & \\
\hline
\end{tabular}



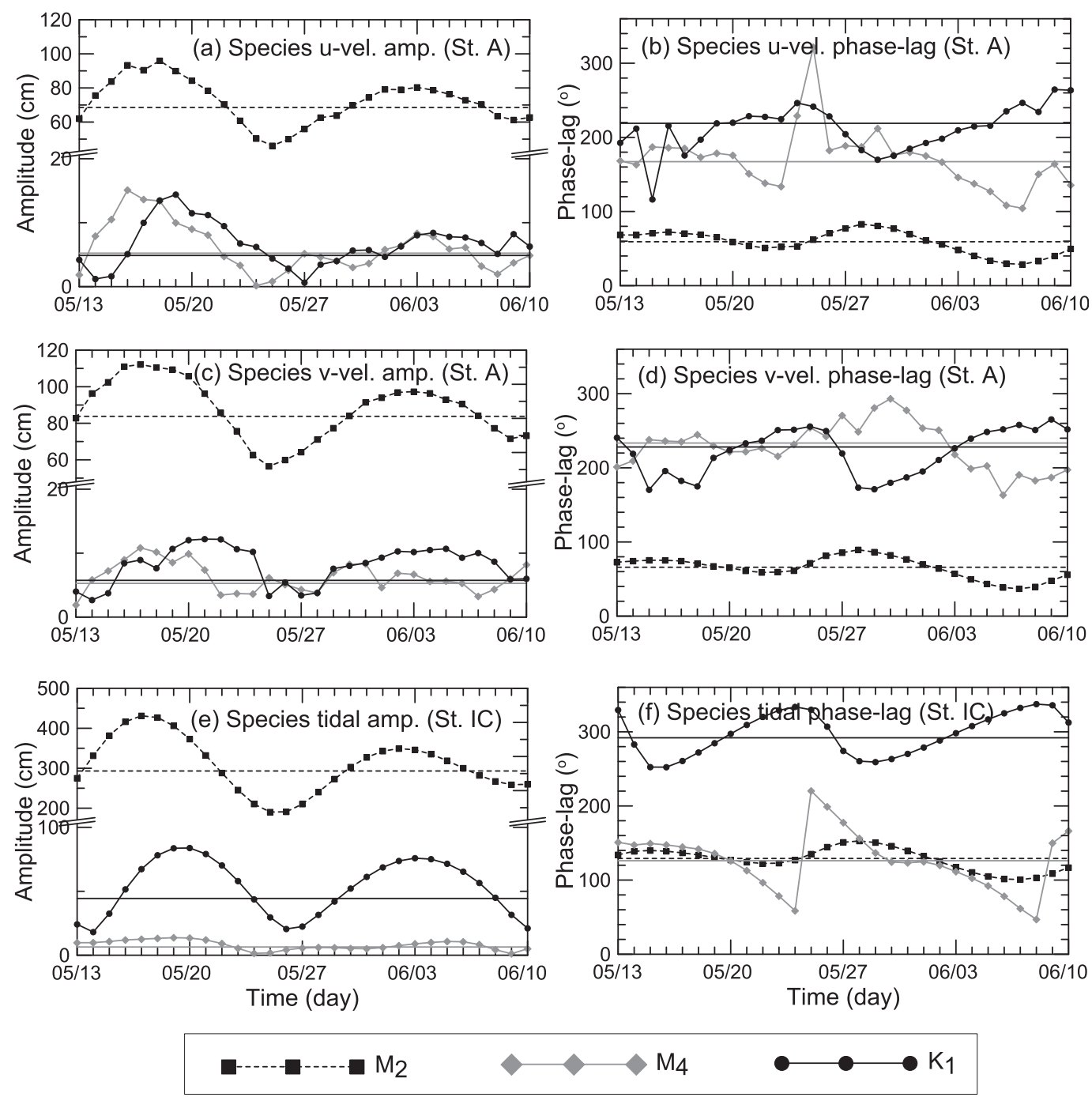

FIG. 3. The daily (left) amplitudes and (right) phase lags of the $\mathrm{K}_{1}, \mathrm{M}_{2}$, and $\mathrm{M}_{4}$ (a),(b) $u$ and (c),(d) $v$ velocity components at station A, and (e),(f) the tides at station IC, calculated from daily data slices of 29-day observation data from 13 May to 10 Jun 2007. Solid $\left(K_{1}\right)$, dashed $\left(M_{2}\right)$, and gray $\left(\mathbf{M}_{4}\right)$ lines in each panel indicate the amplitude ratio and the phase-lag differences for the $\mathrm{K}_{1}$, the $\mathrm{M}_{2}$, and the $\mathrm{M}_{4}$ tides, derived from results of 29-day harmonic analyses of the tidal current and tide station data.

of $\left[\left(a_{o u}^{s} / a_{r \eta}^{s}\right),\left(a_{o v}^{s} / a_{r \eta}^{s}\right),\left(g_{o u}^{s}-g_{r \eta}^{s}\right)\right.$, and $\left.\left(g_{o v}^{s}-g_{r \eta}^{s}\right)\right]$ for Eqs. (15) and (16), for each representative constituent of the three key tidal current species [i.e., diurnal $\left(\mathrm{K}_{1}\right)$, semidiurnal $\left(\mathrm{M}_{2}\right)$, and fourth-diurnal $\left(\mathrm{M}_{4}\right)$ tidal species]. Representative results from station A are illustrated in Figs. 3 and 4, while the means and standard deviations of the input values calculated for all three stations are listed in Table 2.

Last, yearlong (2007) sea level records observed at 10-min intervals from station IC (Fig. 1) were harmonically analyzed to calculate the modulated amplitudes $A_{r \eta}^{s}(\tau)$ and phase lags $\varphi_{r \eta}^{s}(\tau)$ in Eqs. (15) and (16) for each of the three tidal species, as shown in Fig. 5.
Note that values of $A_{r \eta}^{s}(\tau)$ and $\varphi_{r \eta}^{s}(\tau)$ vary over time. For our tidal current predictions, we selected the same 29-day period covered by the current observations to allow for verification of the prediction results against field data.

In this study a harmonic analysis and prediction program, T_Tide (Pawlowicz et al. 2002), was used to generate the input values (daily values for both amplitude ratios and phase-lag differences) for each representative constituent $\left(\mathrm{K}_{1}, \mathrm{M}_{2}\right.$, and $\left.\mathrm{M}_{4}\right)$, as well as the modulated amplitudes and phase lags of the different tidal species. Root-mean-square error (RMSE) statistics were used to compare the tidal components 

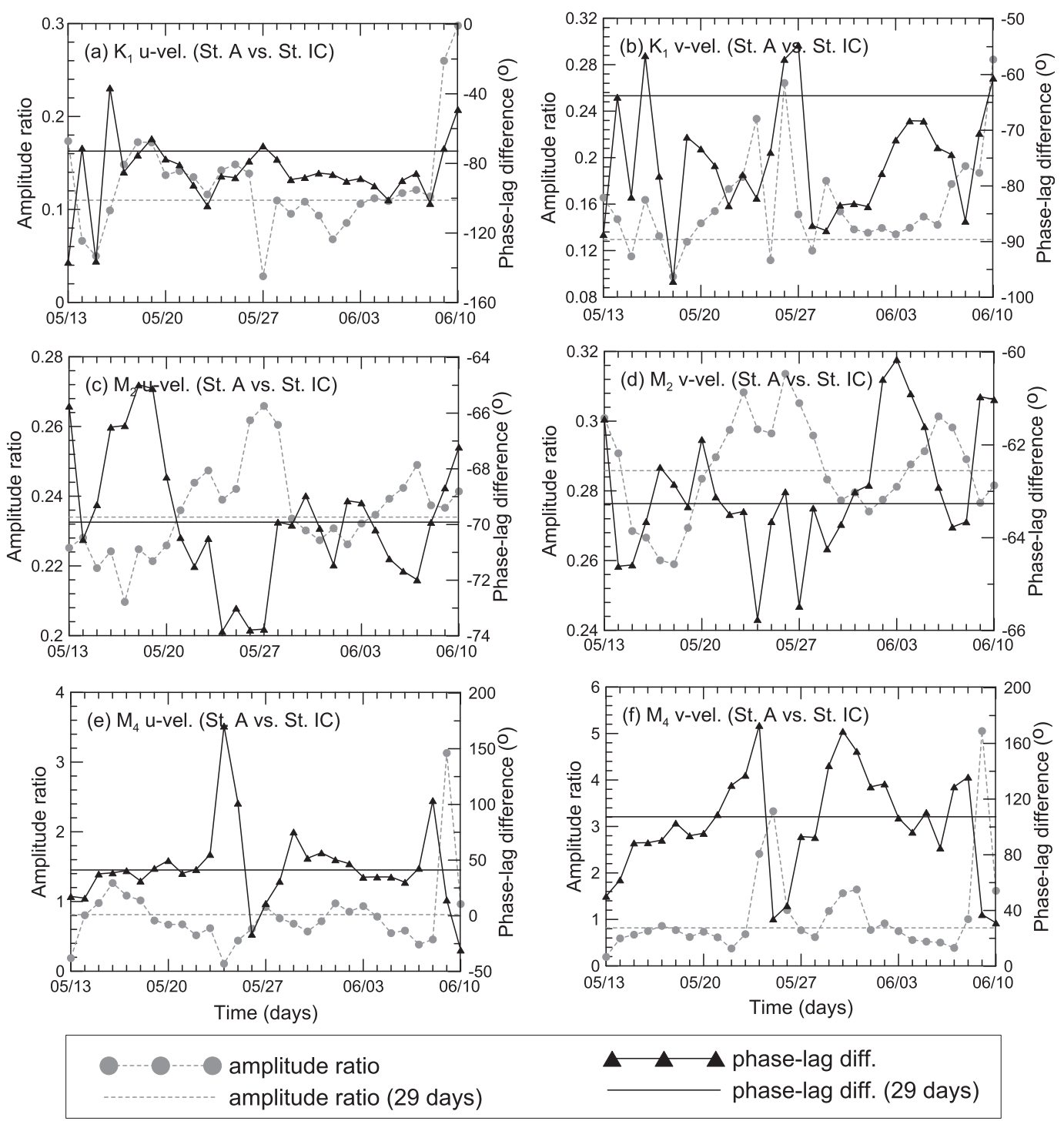

FIG. 4. The daily amplitude ratios and phase-lag differences for three representative constituents $\left(\mathrm{K}_{1}, \mathrm{M}_{2}\right.$, and $\mathrm{M}_{4}$ ) of the diurnal, semidiurnal, and fourth-diurnal species of (a),(c),(e) $u$ and (b),(d),(f) $v$ velocity tidal current components between station A tidal current data and station IC sea level data, derived from harmonic analysis of 29 days of daily $(25 \mathrm{~h})$ data slices. Thick solid and dashed lines in each panel indicate the amplitude ratio and phase-lag differences, respectively, for the $\mathrm{K}_{1}, \mathrm{M}_{2}$, and $\mathrm{M}_{4}$ tides, derived from harmonic analysis of station A 29-day tidal current data.

produced from $\mathrm{T} \_$Tide predictions and our CTSM+TCCC method, versus observations, in order to evaluate the tidal current prediction performance of our CTSM+TCCC approach. It is worth noting that although the study area chosen for the development and testing of this method comprised a region dominated by semidiurnal tides, the method developed is equally applicable to areas with different tidal regimes but similar behavior between tides and tidal currents, including those dominated by diurnal tides, since the method resolves the behavior of diurnal, semidiurnal, and fourth-diurnal tidal and tidal current species.

\section{Results and discussion \\ a. Tidal current prediction capability of the CTSM+TCCC method}

Table 3 shows the result of RMSE comparisons between the tidal current field observations and the tidal current predictions produced using the traditional harmonic prediction (THP) method based on T_Tide 
TABLE 2. Means and standard deviations of the amplitude ratios $\left[\overline{R_{\text {amp }}}( \pm\right.$ std $\left.)\right]$ and phase-lag differences $\left[\overline{D_{\text {pha }}}( \pm\right.$ std $\left.)\right]$ of representative tidal constituents $\left(\mathrm{K}_{1}, \mathrm{M}_{2}\right.$, and $\left.\mathrm{M}_{4}\right)$ for each diurnal, semidiurnal, and fourth-diurnal harmonic species derived using T_Tide, based on daily $(25 \mathrm{~h})$ tidal current observations from stations A-C, over the 29 days from 13 May to 10 Jun 2007; and amplitude ratios $R_{\text {amp }}$ and phase-lag differences $D_{\text {pha }}$ for each $u$ and $v$ velocity component derived from harmonic analysis of the 29-day tidal current records.

\begin{tabular}{|c|c|c|c|c|c|c|c|c|c|}
\hline \multirow[b]{3}{*}{ Station } & \multirow[b]{3}{*}{ Constant } & \multicolumn{4}{|c|}{ 25-h harmonic analysis-derived results } & \multicolumn{4}{|c|}{$\begin{array}{l}\text { 1-month harmonic } \\
\text { analysis-derived results }\end{array}$} \\
\hline & & \multicolumn{2}{|c|}{$u$ velocity } & \multicolumn{2}{|c|}{$v$ velocity } & \multicolumn{2}{|c|}{$u$ velocity } & \multicolumn{2}{|c|}{$v$ velocity } \\
\hline & & $\overline{R_{\mathrm{amp}}}( \pm \mathrm{std})$ & $\overline{D_{\text {pha }}}( \pm$ std $)$ & $\overline{R_{\mathrm{amp}}}( \pm \mathrm{std})$ & $\overline{D_{\text {pha }}}( \pm$ std $)$ & $R_{\text {amp }}$ & $D_{\text {pha }}$ & $R_{\mathrm{amp}}$ & $D_{\text {pha }}$ \\
\hline \multirow[t]{3}{*}{ A } & $\mathrm{K}_{1}$ & $0.127( \pm 0.055)$ & $-85.6^{\circ}\left( \pm 20.2^{\circ}\right)$ & $0.160( \pm 0.042)$ & $-75.6^{\circ}\left( \pm 10.5^{\circ}\right)$ & 0.110 & $-72.9^{\circ}$ & 0.130 & $-63.8^{\circ}$ \\
\hline & $\mathrm{M}_{2}$ & $0.236( \pm 0.013)$ & $-69.8^{\circ}\left( \pm 2.5^{\circ}\right)$ & $0.286( \pm 0.014)$ & $-62.9^{\circ}\left( \pm 1.4^{\circ}\right)$ & 0.234 & $-69.9^{\circ}$ & 0.286 & $-63.3^{\circ}$ \\
\hline & $\mathrm{M}_{4}$ & $0.792( \pm 0.519)$ & $43.1^{\circ}\left( \pm 36.7^{\circ}\right)$ & $1.093( \pm 1.001)$ & $101.5^{\circ}\left( \pm 38.8^{\circ}\right)$ & 0.812 & $41.1^{\circ}$ & 0.818 & $107.3^{\circ}$ \\
\hline \multirow[t]{3}{*}{ B } & $\mathrm{K}_{1}$ & $0.127( \pm 0.054)$ & $-95.8^{\circ}( \pm 15.9)$ & $0.142( \pm 0.027)$ & $-69.1^{\circ}\left( \pm 10.4^{\circ}\right)$ & 0.098 & $-86.2^{\circ}$ & 0.116 & $-58.6^{\circ}$ \\
\hline & $\mathrm{M}_{2}$ & $0.286( \pm 0.016)$ & $-84.6^{\circ}\left( \pm 1.4^{\circ}\right)$ & $0.192( \pm 0.010)$ & $-50.7^{\circ}\left( \pm 2.6^{\circ}\right)$ & 0.284 & $-85.0^{\circ}$ & 0.194 & $-51.4^{\circ}$ \\
\hline & $\mathrm{M}_{4}$ & $0.823( \pm 0.279)$ & $-34.6^{\circ}\left( \pm 31.8^{\circ}\right)$ & $0.487( \pm 0.308)$ & $-34.6^{\circ}\left( \pm 31.8^{\circ}\right)$ & 0.834 & $-39.7^{\circ}$ & 0.359 & $-79.8^{\circ}$ \\
\hline \multirow[t]{3}{*}{$\mathrm{C}$} & $\mathrm{K}_{1}$ & $0.082( \pm 0.028)$ & $-100.5^{\circ}\left( \pm 22.5^{\circ}\right)$ & $0.170( \pm 0.027)$ & $-55.3^{\circ}\left( \pm 9.4^{\circ}\right)$ & 0.054 & $-87.2^{\circ}$ & 0.155 & $-45.9^{\circ}$ \\
\hline & $\mathrm{M}_{2}$ & $0.211( \pm 0.016)$ & $-107.1^{\circ}\left( \pm 2.0^{\circ}\right)$ & $0.165( \pm 0.007)$ & $-11.6^{\circ}\left( \pm 5.9^{\circ}\right)$ & 0.210 & $-107.3^{\circ}$ & 0.167 & $-12.9^{\circ}$ \\
\hline & $\mathrm{M}_{4}$ & $0.507( \pm 0.416)$ & $67.8^{\circ}\left( \pm 49.1^{\circ}\right)$ & $1.100( \pm 0.682)$ & $61.7^{\circ}\left( \pm 29.9^{\circ}\right)$ & 0.357 & $80.6^{\circ}$ & 1.004 & $62.7^{\circ}$ \\
\hline
\end{tabular}

${ }^{a}$ The inference method is applied to separate out $\mathrm{K}_{1}$ and $\mathrm{P}_{1}$ tidal current constituents using the inference parameters calculated from 1-yr harmonic analysis of nearby Incheon tidal station sea level records.

harmonic analysis of 29-day tidal current observation data for the three case study stations with their different tidal current patterns. The RMSE values for the THP method versus field observations range from 5.0 to $7.3 \mathrm{~cm} \mathrm{~s}^{-1}$ for the $u$ velocity components and from 3.3 to $7.6 \mathrm{~cm} \mathrm{~s}^{-1}$ for the $v$ velocity components across the three prediction stations. These RMSE values were calculated to provide an accuracy benchmark for the following CTSM+TCCC prediction experiments.

Next, we conducted three CTSM+TCCC experiments using 29 sets of input data [amplitude ratios
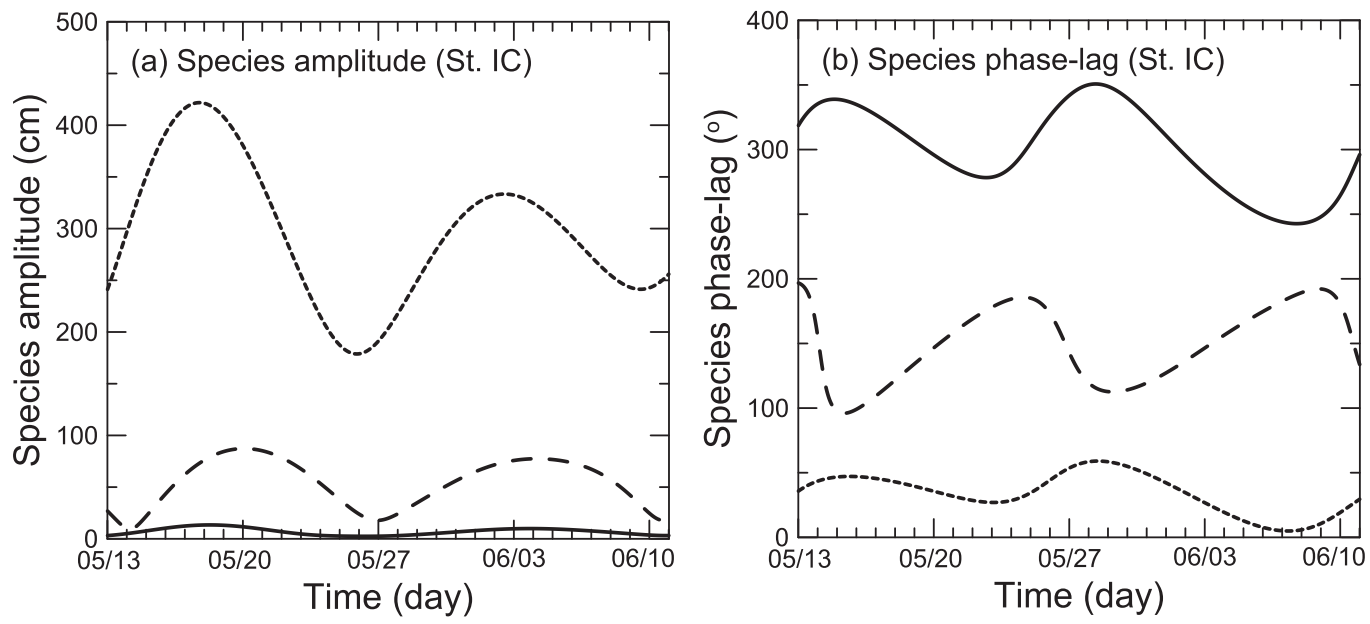

---- Diurnal

Semi-diurnal

Fourth-diurnal

FIG. 5. The 29-day time series from 13 May to 10 Jun 2007 of the species (a) amplitudes and (b) phase lags for the diurnal, semidiurnal, and fourth-diurnal tides, calculated from 2007 station IC sea level observation records, using Eqs. (10) and (11). 
TABLE 3. RMSE comparisons between tidal current field observations from three case study stations (A-C) vs tidal currents generated from (i) a THP method using HAR of 29-day tidal current records and (ii) 29 CTSM+TCCC prediction datasets, each generated using daily $(25 \mathrm{~h})$ tidal current data slices from the prediction station, plus concurrent and long-term 2007 station IC sea level records, and three experimental cases. Here, Mean $=\sum_{d=1}^{29} \operatorname{RMSE}(d) / 29$, with RMSE $=\sqrt{1 /(N-1) \sum_{m=1}^{N}\left(U_{m}^{p}-U_{m}^{o}\right)^{2}}$, where $N=4176, U^{p}$ is the THP result, and $U^{o}$ is the observed tidal current component, with a 10-min tidal current data interval. Std dev denotes the standard deviation of the RMSEs.

\begin{tabular}{|c|c|c|c|c|c|c|c|}
\hline \multirow[b]{2}{*}{ Experiment } & \multirow[b]{2}{*}{ Station } & \multicolumn{2}{|c|}{ A } & \multicolumn{2}{|c|}{$\mathrm{B}$} & \multicolumn{2}{|c|}{$\mathrm{C}$} \\
\hline & & $\begin{array}{c}u \\
\left(\mathrm{~cm} \mathrm{~s}^{-1}\right)\end{array}$ & $\begin{array}{c}v \\
\left(\mathrm{~cm} \mathrm{~s}^{-1}\right)\end{array}$ & $\begin{array}{c}u \\
\left(\mathrm{~cm} \mathrm{~s}^{-1}\right)\end{array}$ & $\begin{array}{c}v \\
\left(\mathrm{~cm} \mathrm{~s}^{-1}\right)\end{array}$ & $\begin{array}{c}u \\
\left(\mathrm{~cm} \mathrm{~s}^{-1}\right)\end{array}$ & $\begin{array}{c}v \\
\left(\mathrm{~cm} \mathrm{~s}^{-1}\right)\end{array}$ \\
\hline THP_RMSE & Overall & 7.3 & 7.6 & 6.6 & 4.5 & 5.0 & 3.3 \\
\hline \multirow{4}{*}{$\begin{array}{l}\text { CTSM+TCCC_RMSE Exp. } 1 \text { (diurnal, } \\
\text { semidiurnal, and fourth-diurnal } \\
\text { species) }\end{array}$} & Minimum & 7.3 & 8.7 & 8.0 & 5.8 & 5.4 & 5.8 \\
\hline & Maximum & 16.4 & 27.9 & 16.4 & 12.5 & 12.3 & 21.2 \\
\hline & Mean & 9.0 & 11.1 & 9.4 & 6.9 & 7.1 & 8.3 \\
\hline & Std dev & 2.0 & 4.0 & 1.7 & 1.4 & 2.1 & 3.5 \\
\hline \multirow{4}{*}{$\begin{array}{l}\text { CTSM+TCCC_RMSE Exp. } 2 \text { (diurnal } \\
\text { and semidiurnal species) }\end{array}$} & Minimum & 8.4 & 9.4 & 8.6 & 5.9 & 5.7 & 7.6 \\
\hline & Maximum & 12.6 & 12.8 & 12.3 & 9.9 & 11.7 & 12.8 \\
\hline & Mean & 9.5 & 10.2 & 9.8 & 6.8 & 7.0 & 8.8 \\
\hline & Std dev & 1.1 & 0.7 & 1.1 & 0.8 & 1.6 & 1.2 \\
\hline \multirow{4}{*}{$\begin{array}{l}\text { CTSM+TCCC_RMSE Exp. } 3 \\
\text { (semidiurnal species) }\end{array}$} & Minimum & 9.8 & 11.1 & 9.7 & 8.3 & 6.4 & 10.7 \\
\hline & Maximum & 12.5 & 13.0 & 13.0 & 11.0 & 11.8 & 14.6 \\
\hline & Mean & 10.4 & 11.7 & 10.4 & 8.8 & 7.4 & 11.5 \\
\hline & Std dev & 0.7 & 0.4 & 0.8 & 0.6 & 1.4 & 0.9 \\
\hline
\end{tabular}

tidal current predictions generated from the three different experimental cases were compared with these stations' tidal current field observations via RMSE.

As shown in Fig. 6, for CTSM+TCCC Exp. 1 the RMSE values for both the $u$ and $v$ velocity components varied over time, roughly in opposite directions to variations in tidal range. For all three stations, for example, maximum RMSE values occurred during neap periods (24-27 May and 9-10 June), and these were over twice the RMSE value of spring periods. However, note that even though the tidal range varied only slightly between 25 and 26 May (and between 9 and 10 June), the RMSE of 26 May (and 10 June) was considerably lower than that of 25 May (and 9 June). In addition, the RMSE at all three stations were higher for 24 May than for 26 May, with the exception of $u$ velocities at station A. As revealed in Fig. 4, these seemingly odd patterns were mainly the result of unstable $\mathrm{M}_{4}$ tidal amplitude ratios and phase-lag differences. These instabilities were, in turn, related to irregular variations in the $\mathrm{M}_{4}$ phase lags (Figs. 4b, 4d, and 4f). During neap tide periods, $\mathrm{M}_{4}$ amplitude ratios and phase lags had relatively high or low values. On spring tide days, these parameters exhibited much less variation, with results approximating those of the 29-day data record's harmonic analysis results (HAR).

By excluding the modulated $\mathrm{M}_{4}$ tides in Exp. 2, we were able to fully explore the importance of this fourth-diurnal modulated species in producing accurate tidal current predictions. Figure 7 reveals that peak RMSE values were significantly reduced, while nonpeak RMSE values increased slightly in Exp. 2 compared to in Exp. 1 across all three stations. With the exception of station A, average increases were around $0.1-0.4 \mathrm{~cm} \mathrm{~s}^{-1}$ for $u$ velocity components and around $0.1-0.5 \mathrm{~cm} \mathrm{~s}^{-1}$ for $v$ velocity components. Because of the large reduction in peak RMSE values, their standard deviations also decreased significantly, from around 1.4 to $4 \mathrm{~cm} \mathrm{~s}^{-1}$ in Exp. 1 and from around 0.7 to $1.2 \mathrm{~cm} \mathrm{~s}^{-1}$ in Exp. 2 (Table 3). These results suggest that the CTSM+TCCC method does not produce reliable predictions based on tidal current observation records from neap tide periods, since the fourth-diurnal species harmonic constant inputs are incorrectly resolved from neap tide data. Our experiments also reveal that maximum RMSE values correlate exactly with days of minimum tidal range, and that there is an approximately 1-day time lag between minimum tides and minimum tidal currents. Note that shallow-water harmonic constituents, including the fourth-diurnal constituents, are generated by nonlinear processes, such as bottom friction, tidal interactions with the bathymetry of the area, and advection in shallow waters (Byun and Cho 2006).

Last, we considered the accuracy of CTSM+TCCC predictions based on only the modulated semidiurnal species (Exp. 3) for all three stations, to explore the importance of the modulated diurnal species in prediction accuracy. Compared to Exp. 2, the RMSE values in Exp. 3 were slightly greater: that is, values 

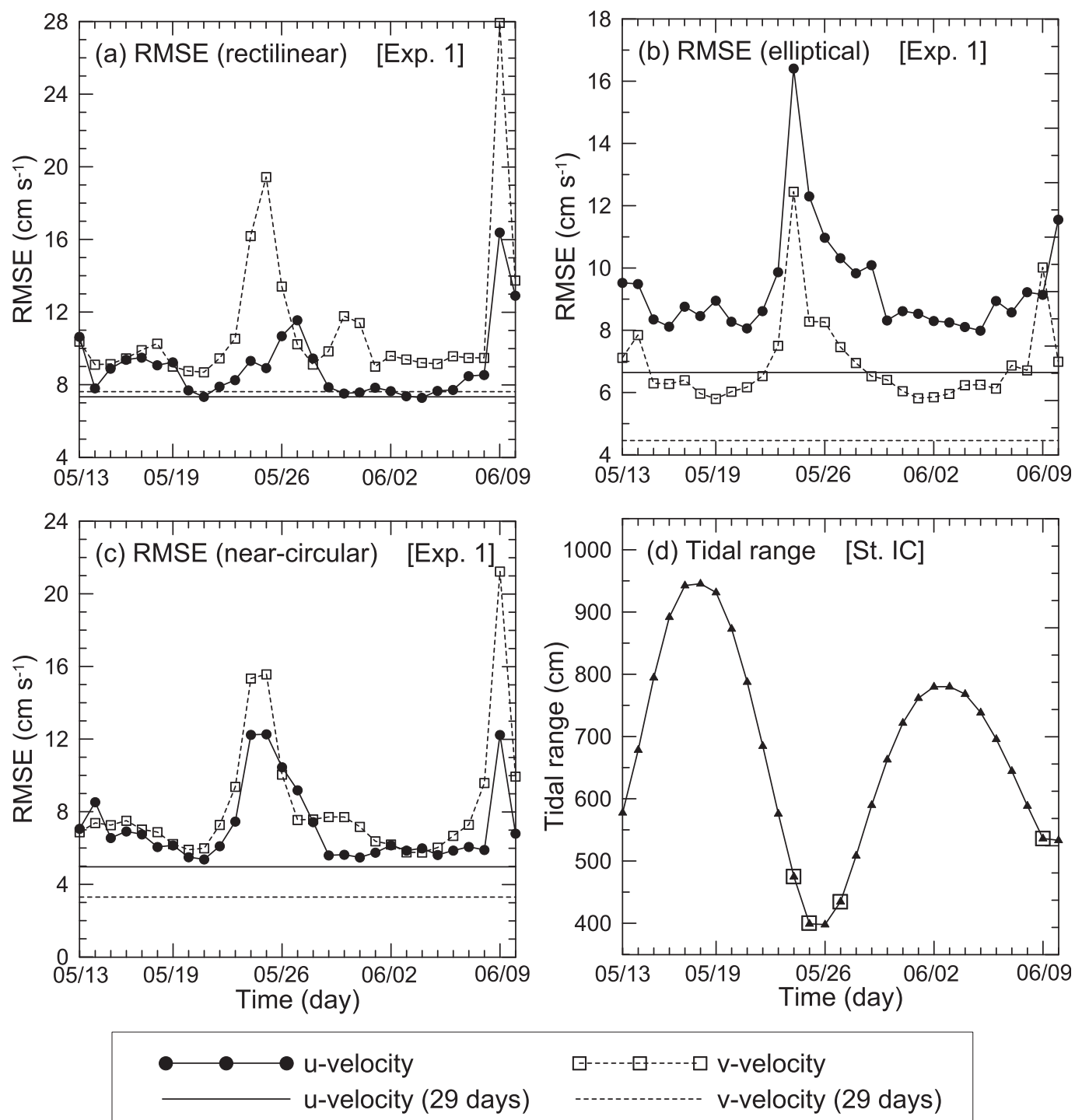

$$
\text { ๑- } \boxminus---\boxminus \text { v-velocity }
$$

FIG. 6. (a)-(c) Time series of RMSE values between 29 days of observed tidal currents and 29 CTSM+TCCC Exp. 1 prediction datasets, each generated using daily $(25 \mathrm{~h})$ tidal current data slices from prediction stations A-C (with their different current patterns indicated), plus concurrent and long-term 2007 station IC sea level records. The thick solid ( $u$ velocity component) and dashed ( $v$ velocity component) lines in (a) $-(\mathrm{c})$ indicate the RMSEs between the 29-day predictions derived from harmonic analysis vs observations. (d) A tidal range time series for station IC, calculated from the maximum and minimum values of daily ( $25 \mathrm{~h})$ tidal data; open squares highlight days with maximum RMSE values between the predicted and observed current components [i.e., as shown in (a)-(c)].

increased on average by $0.4-0.9 \mathrm{~cm} \mathrm{~s}^{-1}$ for $u$ velocity components and by $1.5-2.7 \mathrm{~cm} \mathrm{~s}^{-1}$ for $v$ velocity components (Table 3 ).

The three experiments' results clearly demonstrate that the CTSM+TCCC method can be used to generate reasonably accurate tidal current predictions based on 25-h tidal current records collected during spring tide periods, such as those collected by the KHOA. In addition, even though the RMSE values of predictions generated using data from neap tide monitoring periods are relatively high, these values are still within a reasonable range (as shown in Exp. 2 and Exp. 3) when compared to the RMSE of predictions generated via THP techniques using 29-day observation data. This is because variations in the amplitude ratios and phase-lag differences of the predominant $\mathrm{M}_{2}$ tidal current constituent are relatively small, with standard deviations of the $u$ and 

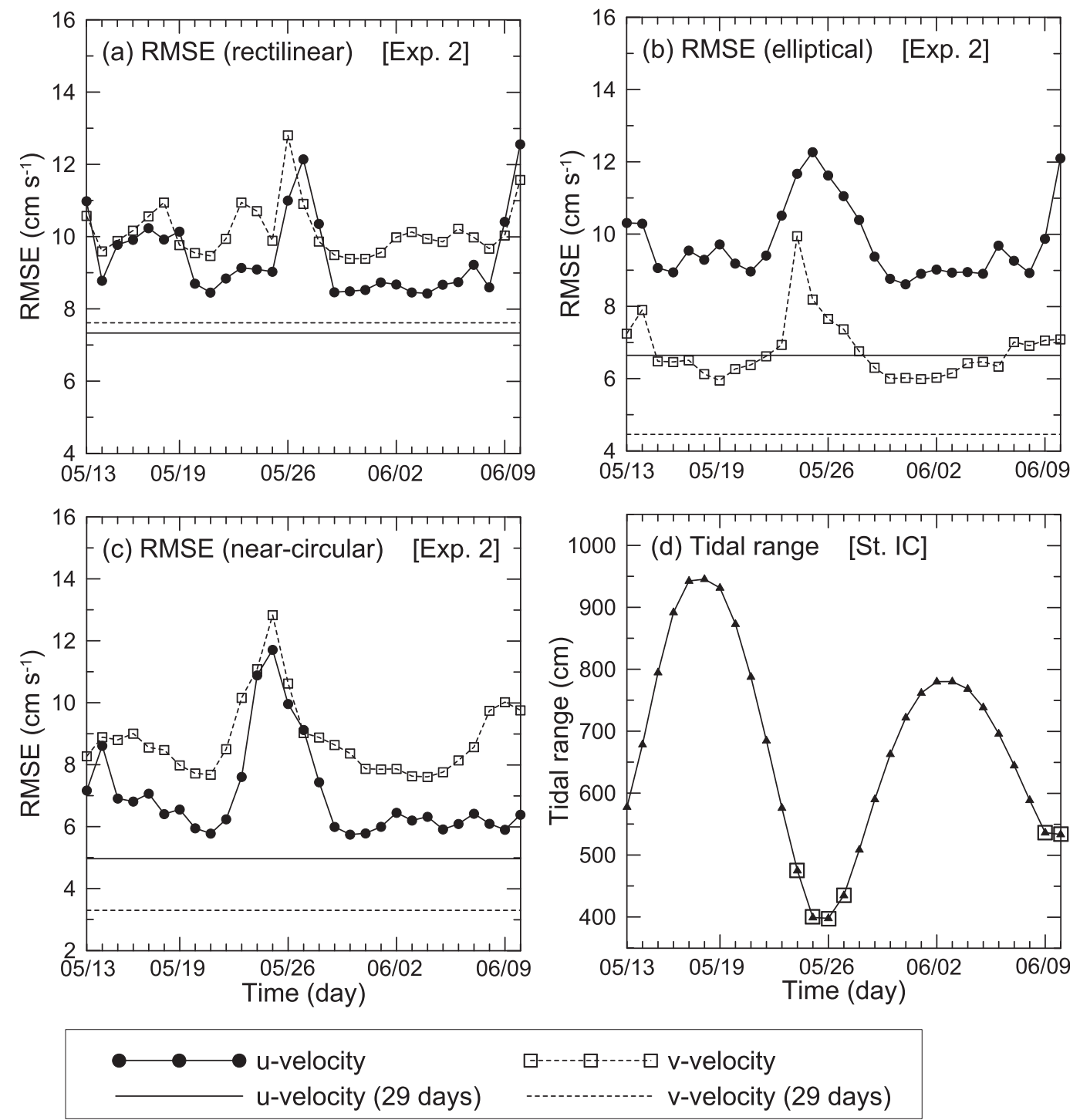

FIG. 7. As in Fig. 6, but for Exp. 2.

$v$ velocity components being $0.01 \mathrm{~cm} \mathrm{~s}^{-1}$ and $1^{\circ}$, respectively (Table 2).

\section{b. Prediction capability of the CTSM+TCCC method using reference records from spatially separated sites characterized by different tidal regimes}

Tidal current prediction accuracy through the CTSM+TCCC method in Eqs. (15) and (16) depends on reference station tidal height harmonic inputs, including calculated amplitude ratios and phase-lag differences as well as modulated amplitudes and phase lags for each representative constituent. These input variables vary across different types of tidal regime, with similar (different) regimes tending to occur in proximal (spatially separated) locations.
Accordingly, in this section, we explore the sensitivity of the CTSM+TCCC method to the relative locations of example temporary and different reference stations: that is, does result accuracy vary between predictions based on reference stations that are spatially close versus far, and therefore located in similar versus different tidal regimes, from the temporary tidal station?

As mentioned in section 4, the tidal currents of stations $\mathrm{A}-\mathrm{C}$ are all characterized by regimes dominated by semidiurnal constituent influences, notably $\mathrm{M}_{2}$ and $\mathrm{S}_{2}$. Thus, to simplify our tests for prediction result sensitivity to reference station location, we examined prediction accuracy for only the semidiurnal tidal species (i.e., CTSM+TCCC Exp. 3). We also 
TABLE 4. Variation in the accuracy of CTSM+TCCC Exp. 3 results in relation to reference station location: accuracy is gauged via RMSE means and standard deviations (StdD) of tidal current predictions made using 29 daily $(25 \mathrm{~h})$ tidal current data slices from Station A, plus sea level data from 20 different tidal reference stations from the west and south coasts of Korea.

\begin{tabular}{|c|c|c|c|c|c|c|c|}
\hline \multirow{2}{*}{\multicolumn{2}{|c|}{ Reference tidal station }} & \multirow{3}{*}{$\begin{array}{c}\text { Year } \\
2009\end{array}$} & \multirow{3}{*}{$\begin{array}{c}\begin{array}{c}\text { Distance } \\
(\mathrm{km})\end{array} \\
123.9\end{array}$} & \multicolumn{2}{|c|}{ RMSE ( $u$ velocity) } & \multicolumn{2}{|c|}{ RMSE ( $v$ velocity) } \\
\hline & & & & \multirow{2}{*}{$\begin{array}{c}\begin{array}{c}\text { Mean } \\
\left(\mathrm{cm} \mathrm{s}^{-1}\right)\end{array} \\
12.7\end{array}$} & \multirow{2}{*}{$\frac{\begin{array}{c}\mathrm{StdD} \\
\left(\mathrm{cm} \mathrm{s}^{-1}\right)\end{array}}{2.2}$} & \multirow{2}{*}{$\begin{array}{c}\begin{array}{c}\text { Mean } \\
\left(\mathrm{cm} \mathrm{s}^{-1}\right)\end{array} \\
14.0\end{array}$} & \multirow{2}{*}{$\frac{\begin{array}{c}\mathrm{StdD} \\
\left(\mathrm{cm} \mathrm{s}^{-1}\right)\end{array}}{2.1}$} \\
\hline West Coast Group & DC (Daecheongdo) & & & & & & \\
\hline & IC (Incheon) & 2007 & 45.1 & 10.4 & 0.7 & 11.7 & 0.4 \\
\hline & YH (Yeongheungdo) & 2014 & 47.3 & 10.5 & 0.7 & 12.0 & 0.6 \\
\hline & GU (Gulupdo) & 2010 & 43.7 & 11.1 & 1.3 & 12.4 & 1.1 \\
\hline & DS (Daesan) & 2013 & 67.1 & 10.8 & 0.9 & 12.2 & 0.9 \\
\hline & TA (Taean) & 2011 & 74.9 & 10.9 & 1.0 & 12.2 & 0.8 \\
\hline & AH (Anheung) & 2011 & 100.6 & 11.2 & 1.3 & 12.4 & 1.1 \\
\hline & BR (Boryeong) & 2011 & 134.6 & 11.0 & 1.1 & 12.3 & 0.9 \\
\hline & EC (Eocheongdo) & 2011 & 162.8 & 11.5 & 1.4 & 12.6 & 1.2 \\
\hline & MR (Maryang) & 2012 & 164.8 & 11.4 & 1.3 & 12.6 & 1.1 \\
\hline & WI (Wido) & 2014 & 218.7 & 11.2 & 1.1 & 12.2 & 0.9 \\
\hline & YG (Yeonggwang) & 2011 & 241.0 & 11.5 & 1.5 & 12.6 & 1.3 \\
\hline & MP (Mokpo) & 2011 & 312.1 & 12.1 & 1.7 & 13.4 & 1.7 \\
\hline & HS (Heuksando) & 2005 & 327.4 & 12.8 & 1.6 & 13.8 & 1.6 \\
\hline \multirow[t]{6}{*}{ South Coast Group } & JD (Jindo) & 2012 & 356.4 & 16.7 & 4.2 & 18.9 & 4.9 \\
\hline & WD (Wando) & 2003 & 367.5 & 18.0 & 5.2 & 20.7 & 6.1 \\
\hline & CJ (Chujado) & 2015 & 402.5 & 18.2 & 4.7 & 20.5 & 5.5 \\
\hline & $\mathrm{JJ}(\mathrm{Jeju})$ & 2007 & 452.2 & 19.4 & 6.0 & 22.2 & 7.1 \\
\hline & TY (Tongyeong) & 2007 & 620.7 & 16.6 & 4.0 & 19.2 & 4.9 \\
\hline & BS (Busan) & 2003 & 683.0 & 16.5 & 4.3 & 19.3 & 5.2 \\
\hline
\end{tabular}

used station A as our sole "temporary" tidal current observation and prediction site, with input data from this site comprising 29 separate 25 -h tidal current observation data "slices." As reference site input data, we employed yearlong sea level observations from 20 stations located along South Korea's west and south coasts, with stations varying between 40 and $683 \mathrm{~km}$ from the station A "prediction" site. The test predictions were then compared to actual station A tidal current observations via RMSE analysis. The results indicate that errors generally increased with increasing distance between station $\mathrm{A}$ and the reference tidal station, with mean error values ranging from $10.4 \mathrm{~cm} \mathrm{~s}^{-1}$ (using reference station IC, $45 \mathrm{~km}$ distant) to $19.4 \mathrm{~cm} \mathrm{~s}^{-1}$ (using reference station $\mathrm{JJ}$, $452 \mathrm{~km}$ distant) for $u$ velocities; and from $11.7 \mathrm{~cm} \mathrm{~s}^{-1}$ (using reference station IC) to $22.2 \mathrm{~cm} \mathrm{~s}^{-1}$ (using station $\mathrm{JJ}$ ) for $v$ velocities. The RMSE results from this test were clustered into two groups based on general geographic location (west vs south coasts) and RMSE values (Table 4). For the west coast group, the $u$ velocity RMSE values ranged from 10.4 to $12.8 \mathrm{~cm} \mathrm{~s}^{-1}$ from station IC to station HS (HS being $327 \mathrm{~km}$ distant), while the $v$ velocity RMSE values range from 11.7 to $14.0 \mathrm{~cm} \mathrm{~s}^{-1}$, from station IC to station DC (DC being $124 \mathrm{~km}$ distant). For group S, the $u$ velocity RMSE values range from 16.5 to $19.4 \mathrm{~cm} \mathrm{~s}^{-1}$, from station BS to station $\mathrm{JJ}$, while the $v$ velocity RMSE values range from 18.9 to $22.2 \mathrm{~cm} \mathrm{~s}^{-1}$, from station JD $(356 \mathrm{~km}$ distant) to station JJ. These test results indicate that the proximity of reference to prediction stations is important, with predictions made using data from reference stations situated in nearby similar tidal regimes generally having greater accuracy than those made using distant reference stations. Below we further explore possible reasons for variation in the RMSE values in these "location accuracy effect" tests.

First, we reran some tests using data on three tidal species as opposed to one (i.e., Exp. 1 as opposed to Exp. 3). The 29-daily values of RMSE for Exp. 1 (Fig. 6) at two example reference stations using three tidal species averaged 9.0 and $11.1 \mathrm{~cm} \mathrm{~s}^{-1}$ for $u$ and $v$ velocities at station IC and 18.9 and $21.6 \mathrm{~cm} \mathrm{~s}^{-1}$ for $u$ and $v$ velocities at station JJ, respectively. These results show small reductions in RMSE values of $<1.5 \mathrm{~cm} \mathrm{~s}^{-1}$ compared to the Exp. 3 (Fig. 8) results obtained using semidiurnal species alone, confirming the validity of our simplified accuracy testing approach.

Second, we note that our CTSM+TCCC location effect tests were predicated on the idea that the modulated tidal and tidal currents for each species vary spatially in similar ways around the coasts of South Korea. Based on this assumption, we used the amplitude ratio and phase-lag difference of one tidal constituent to represent each species in the reference station input data to generate predictions for our 

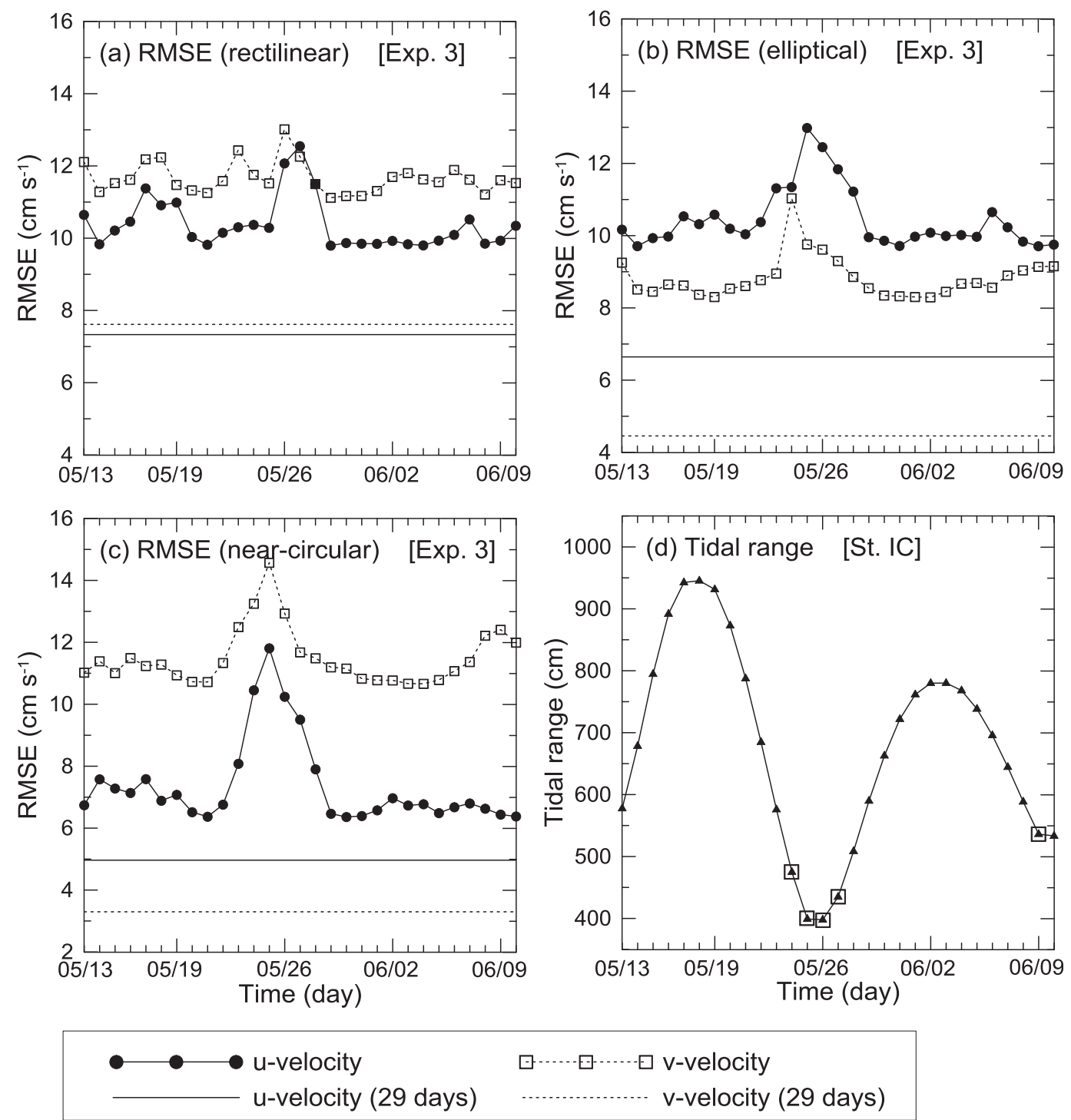

FIG. 8. As in Fig. 6, but for Exp. 3.

temporary tidal current station. However, in order to verify the validity of this assumption, we examined the spatial phase-lag differences $\left(g_{\mathrm{S}_{2}}-g_{\mathrm{M}_{2}}\right)$ for the two largest tidal constituents, the $\mathrm{M}_{2}$ and the $\mathrm{S}_{2}$ tides, showing the characteristics of the modulated semidiurnal phase lag induced by these important tidal constituents by exploring the horizontal distribution of the age of the tide $A_{T d}$ as calculated by (Pugh 1987):

$$
A_{T d}(\text { day })=\left(\frac{g_{\mathrm{S}_{2}}-g_{\mathrm{M}_{2}}}{\omega_{\mathrm{S}_{2}}-\omega_{\mathrm{M}_{2}}}\right) / 24,
$$

where $\quad \omega_{\mathrm{M}_{2}}\left(=28.984104156^{\circ} \mathrm{h}^{-1}\right)$ and $\omega_{\mathrm{S}_{2}}(=$ $30.000000000^{\circ} \mathrm{h}^{-1}$ ) are the angular speeds of the $\mathrm{M}_{2}$ and $\mathrm{S}_{2}$ tides, respectively.
The reference stations' tidal age results are listed in Table 5. Similar tidal age or $A_{T d}$ values indicate spatially similar modulated semidiurnal phase-lag behavior. Overall, the tidal age values varied between 1.204 days at station $\mathrm{JJ}$ on the south coast and 2.355 days at station IC in Gyeonggi Bay on the west coast. Tidal age values in the vicinity of station A (i.e., southern Gyeonggi Bay stations IC, YH, GU, DS, and TA) ranged from 2.235 days (station $\mathrm{Gu}$ ) to 2.355 days (station IC). The similar tidal age values between these station A proximal reference stations correlate with the stations that produced the most accurate station A tidal current predictions, that is, with CTSM+TCCC RMSE values of $10.4-11.1 \mathrm{~cm} \mathrm{~s}^{-1}$ for $u$ velocities and $11.7-12.4 \mathrm{~cm} \mathrm{~s}^{-1}$ for $v$ velocities. In contrast, the south 
TABLE 5. Details of the four major tidal harmonic constants (amplitudes $a_{o}$ and phase lags $g_{o}$ ), mean spring tide ranges (MSR), tide ages $A_{T d}$, and form factors $\left[F=\left(a_{\mathrm{K}_{1}}+a_{\mathrm{O}_{1}}\right) /\left(a_{\mathrm{M}_{2}}+a_{\mathrm{S}_{2}}\right)\right]$ calculated using tidal harmonic analyses of yearlong sea level observation records from 20 reference tidal observation stations. SD and MSD denote semidiurnal form and mixed, predominantly semidiurnal form, respectively.

\begin{tabular}{|c|c|c|c|c|c|c|c|c|c|c|c|c|c|}
\hline \multirow[b]{2}{*}{$\begin{array}{c}\text { Reference tidal } \\
\text { station }\end{array}$} & \multirow[b]{2}{*}{ Year } & \multicolumn{2}{|c|}{$\mathrm{M}_{2}$} & \multicolumn{2}{|c|}{$\mathrm{S}_{2}$} & \multicolumn{2}{|c|}{$\mathrm{K}_{1}$} & \multicolumn{2}{|c|}{$\mathrm{O}_{1}$} & \multirow[b]{2}{*}{$\begin{array}{l}\text { MSR } \\
(\mathrm{cm})\end{array}$} & \multirow[b]{2}{*}{$\begin{array}{c}A_{T d} \\
\text { (days) }\end{array}$} & \multirow[b]{2}{*}{$F$} & \multirow[b]{2}{*}{ Form } \\
\hline & & $\begin{array}{c}a_{o} \\
(\mathrm{~cm})\end{array}$ & $g_{o}\left({ }^{\circ}\right)$ & $\begin{array}{c}a_{o} \\
(\mathrm{~cm})\end{array}$ & $g_{o}\left({ }^{\circ}\right)$ & $\begin{array}{c}a_{o} \\
(\mathrm{~cm})\end{array}$ & $g_{o}\left({ }^{\circ}\right)$ & $\begin{array}{l}a_{o} \\
(\mathrm{~cm})\end{array}$ & $g_{o}\left({ }^{\circ}\right)$ & & & & \\
\hline DC (Daecheongdo) & 2009 & 108 & 169 & 43 & 219 & 35 & 319 & 26 & 277 & 302 & 2.054 & 0.40 & MSD \\
\hline IC (Incheon) & 2007 & 287 & 129 & 116 & 187 & 40 & 303 & 29 & 264 & 806 & 2.355 & 0.17 & SD \\
\hline $\begin{array}{l}\text { YH } \\
\text { (Yeongheungdo) }\end{array}$ & 2014 & 262 & 126 & 105 & 183 & 38 & 302 & 28 & 263 & 734 & 2.329 & 0.18 & SD \\
\hline GU (Gulupdo) & 2010 & 229 & 123 & 92 & 177 & 38 & 300 & 28 & 261 & 642 & 2.235 & 0.20 & SD \\
\hline DS (Daesan) & 2013 & 246 & 118 & 98 & 174 & 38 & 297 & 28 & 259 & 688 & 2.285 & 0.19 & SD \\
\hline TA (Taean) & 2011 & 232 & 114 & 93 & 169 & 37 & 295 & 28 & 256 & 650 & 2.237 & 0.20 & SD \\
\hline AH (Anheung) & 2011 & 209 & 102 & 83 & 155 & 35 & 290 & 27 & 251 & 584 & 2.170 & 0.21 & SD \\
\hline BR (Boryeong) & 2011 & 227 & 94 & 89 & 148 & 35 & 285 & 27 & 247 & 632 & 2.209 & 0.20 & SD \\
\hline MR (Maryang) & 2012 & 215 & 85 & 84 & 138 & 35 & 280 & 26 & 243 & 598 & 2.148 & 0.20 & SD \\
\hline EC (Eocheongdo) & 2011 & 184 & 87 & 72 & 139 & 33 & 283 & 25 & 245 & 512 & 2.146 & 0.23 & SD \\
\hline WI (Wido) & 2014 & 196 & 75 & 76 & 127 & 33 & 276 & 25 & 238 & 544 & 2.144 & 0.21 & SD \\
\hline YG (Yeonggwang) & 2011 & 201 & 70 & 77 & 122 & 33 & 272 & 26 & 235 & 556 & 2.124 & 0.21 & SD \\
\hline HS (Heuksando) & 2005 & 107 & 42 & 37 & 89 & 24 & 258 & 18 & 227 & 288 & 1.947 & 0.29 & MSD \\
\hline MP (Mokpo) & 2011 & 144 & 38 & 50 & 88 & 31 & 252 & 24 & 217 & 388 & 2.048 & 0.28 & MSD \\
\hline JD (Jindo) & 2012 & 108 & 330 & 42 & 3 & 29 & 219 & 22 & 186 & 300 & 1.386 & 0.34 & MSD \\
\hline WD (Wando) & 2003 & 103 & 296 & 44 & 328 & 27 & 206 & 19 & 172 & 294 & 1.324 & 0.32 & MSD \\
\hline CJ (Chujado) & 2015 & 89 & 327 & 35 & 359 & 27 & 221 & 20 & 190 & 248 & 1.300 & 0.38 & MSD \\
\hline $\mathrm{JJ}$ (Jeju) & 2007 & 68 & 315 & 27 & 345 & 23 & 220 & 17 & 191 & 190 & 1.204 & 0.42 & MSD \\
\hline TY (Tongyeong) & 2007 & 76 & 252 & 35 & 287 & 15 & 180 & 10 & 148 & 222 & 1.452 & 0.22 & SD \\
\hline BS (Busan) & 2003 & 38 & 240 & 18 & 276 & 4 & 146 & 2 & 106 & 112 & 1.483 & 0.11 & SD \\
\hline
\end{tabular}

coast station age of the tide values varied from 1.204 days (station $\mathrm{JJ}$ ) to 1.483 days (station BS), corresponding to reference sites that produced less accurate station A tidal current predictions: with RMSE values from 16.5 to $19.4 \mathrm{~cm} \mathrm{~s}^{-1}$ for $u$ velocities and from 18.9 to $22.2 \mathrm{~cm} \mathrm{~s}^{-1}$ for $v$ velocities (Fig. 9). These results show that the modulated semidiurnal phase lag varies spatially along the coasts of South Korea, thus explaining why proximity between reference and prediction stations influences the accuracy of CTSM+TCCC results, and confirming that CTSM+TCCC tidal current predictions are ideally generated from reference and prediction station sites located in tidal regimes of similar tidal characteristics.

Another possible influence on the accuracy of CTSM+TCCC predictions requiring exploration is the fact that we used reference station tidal height records rather than tidal current records because of the absence of long-term tidal current observations: that is, our results could be affected by differences in the age of the tide versus the age of the tidal currents (e.g., Holloway and Merrifield 2003). Accordingly, we explored the spatial distribution of the age of the tidal current $u$ and $v$ velocities along the west and south coastal zones of South Korea using the Finite Element Solution (FES) 2014 (Carrere et al. 2015) tide model database. Figure 10 shows that the age of the $u$ and $v$ velocities were generally $>2.3$ days in Gyeonggi Bay, with younger values along the south coast. Figure 10a illustrates the modeled age of the tide (i.e., elevation) results, which corresponds well with the Table 5 observation-derived results. Figures $10 \mathrm{~b}$ and $10 \mathrm{c}$ show that the spatial distribution of the age of the tide is generally slightly younger than that of the age of the tidal current $u$ velocities but slightly older than the age of the $v$ velocities. These comparisons between the age of the tide and tidal currents around the west and south coastal zones of South Korea confirm the validity of the CTSM+TCCC approach when using long-term tide records from a nearby reference station, and they illustrate why predictions generated from observations at spatially distant reference and prediction stations are less accurate.

\section{Conclusions}

In this study we show that the complete tidal species modulation with tidal current constant correction (CTSM+TCCC) method enables the generation of accurate tidal current predictions for new locations based on as little as $25 \mathrm{~h}$ of in situ spring tide current observations plus long-term sea level records from nearby "reference" tidal observation stations. This method has been shown to successfully generate 

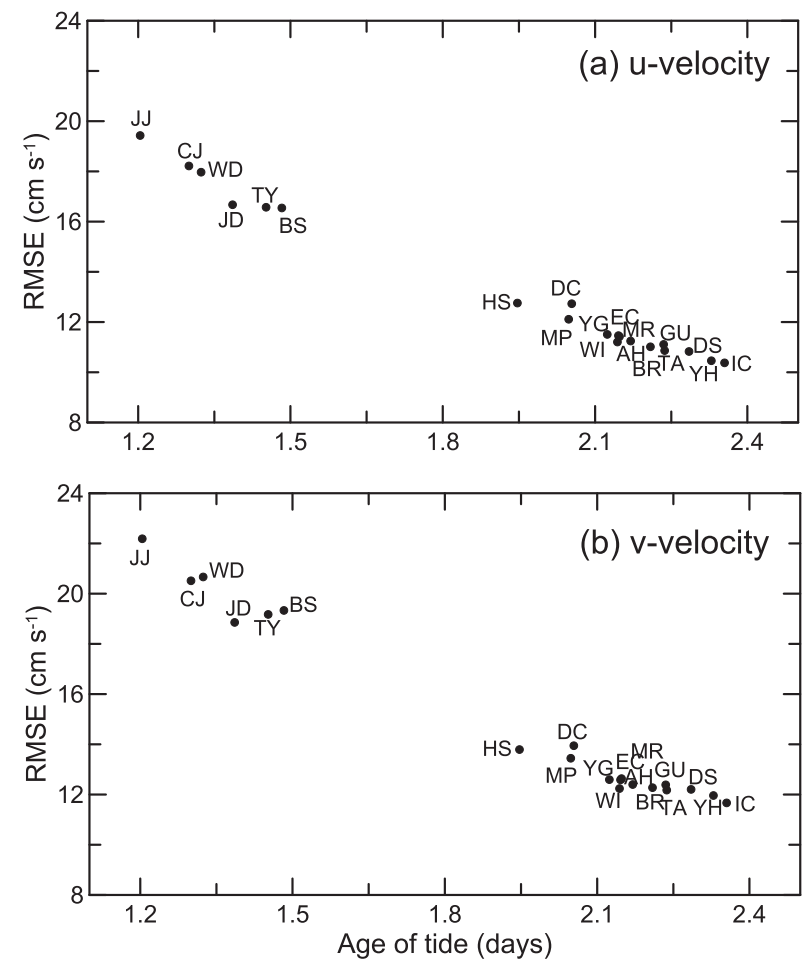

FIG. 9. Relationship between reference station tidal age and mean RMSE values between tidal current observations and CTSM+TCCC Exp. 3 results derived from 20 different reference tidal observation stations (see Table 4 for details of the RMSE data and results).

tidal current predictions for new sites characterized by different tidal current forms (almost rectilinear, elliptical, near circular). Thus, the CTSM+TCCC method expands the practical uses of short-term $(\geq 25 \mathrm{~h})$ tidal current records from spring tide observation periods, such as those gathered by KOHA. When basing CTSM+TCCC predictions on minimum duration current observations (i.e., as little as $25 \mathrm{~h}$ ), additional quality control can be achieved by using current data collected during periods of calm synoptic conditions, thereby minimizing errors resulting from nontidal currents caused by atmospheric influences, and by using at least $25-\mathrm{h}$ current records only for sites in tide-dominated coastal regimes, thereby minimizing errors caused by baroclinic influences.

Alternatively, this new method can be used to generate long-term ( $>6$ months) tidal current predictions for new temporary observation sites, predictions that then can be harmonically analyzed to produce the input data required by established conventional harmonic constant-based tidal current prediction systems. Via such practical applications, the new CTSM+TCCC method has the potential to expand our knowledge of the detailed tidal current
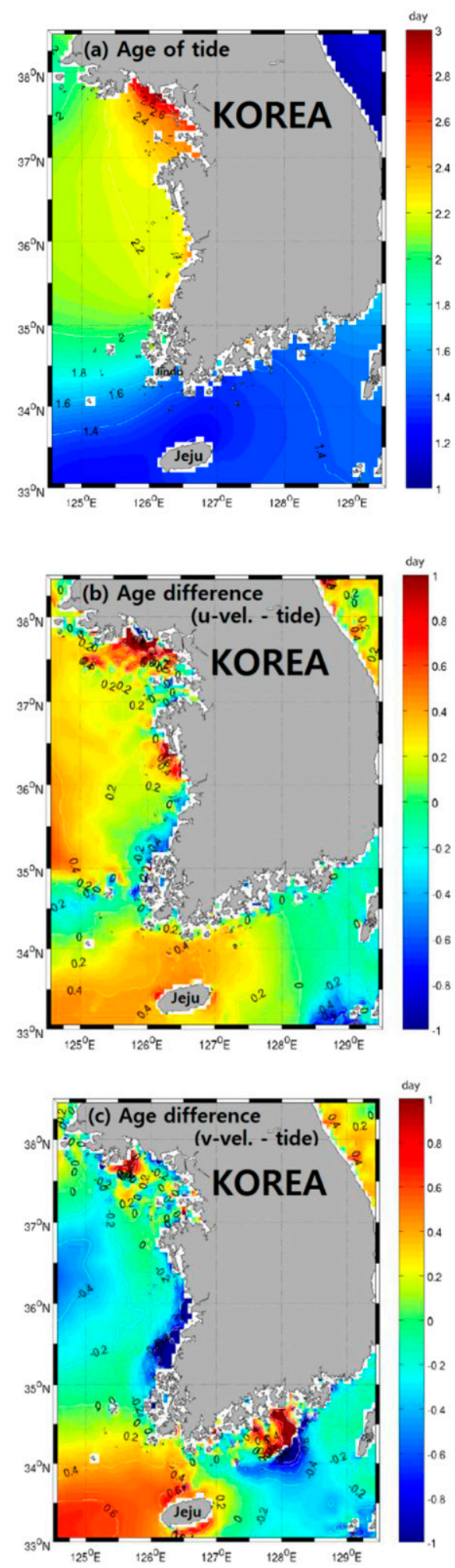

FIG. 10. Spatial variation in the age of (a) tide, and differences between the age of the tide and the age of tidal current (b) $u$ and (c) $v$ velocities around the west and south coastal zones of South Korea. 
patterns existing in the world's tide-dominated coastal environments.

Acknowledgments. We gratefully acknowledge the two reviewers for their comments, which were useful in polishing our paper. Thank you to the Ministry of Oceans and Fisheries of the Republic of Korea for financial support.

\section{REFERENCES}

Byun, D.-S., 2011: Investigating the adjustment methods of monthly variability in tidal current harmonic constants (in Korean). Ocean Polar Res., 33, 309-319, https://doi.org/10.4217/ OPR.2011.33.3.309.

—_ and Y.-K. Cho, 2006: Double peak-flood current asymmetry in a shallow-water-constituent dominated embayment with a macro-tidal flat. Geophys. Res. Lett., 33, L16613, https:// doi.org/10.1029/2006GL026967.

— tions using $25 \mathrm{~h}$ of in situ sea level observations plus reference site records: A complete tidal species modulation with tidal constant corrections. J. Atmos. Oceanic Technol., 32, 350-371, https://doi.org/10.1175/JTECH-D-14-00030.1.

Carrere, L., F. Lyard, M. Cancet, and A. Guillot, 2015: FES 2014, a new tidal model on the global ocean with enhanced accuracy in shallow seas and in the Arctic region. Geophysical Research Abstracts, Vol. 17, Abstract 5481, https://meetingorganizer.copernicus.org/EGU2015/ EGU2015-5481-1.pdf.

Emery, W. J., and R. E. Thomson, 1998: Data Analysis Methods in Physical Oceanography. Pergamon, 643 pp.

Foreman, M. G. G., 1978: Manual for tidal currents analysis and prediction. Institute of Ocean Sciences Pacific Marine Science Rep. 78-6, 57 pp.

Holloway, P. E., and M. A. Merrifield, 2003: On the springneap variability and age of the internal tide at the Hawaiian Ridge. J. Geophys. Res., 108, 3126, https://doi.org/10.1029/ 2002JC001486.

Pawlowicz, R., B. Beardsley, and S. Lentz, 2002: Classical tidal harmonic analysis including error estimates in MATLAB using T_TIDE. Comput. Geosci., 28, 929-937, https://doi.org/ 10.1016/S0098-3004(02)00013-4.

Pugh, D. T., 1987: Tides, Surges and Mean Sea Level: A Handbook for Engineers and Scientists. John Wiley \& Sons, $472 \mathrm{pp}$. 